DOI: $10.17805 /$ trudy.2017.4.8

\title{
РЕФЛЕКСИВНЫЙ ПОДХОД КАК ПЕДАГОГИЧЕСКАЯ ПРОБЛЕМА
}

\author{
Л. С. Бурдякова \\ Московский гуманитарный университет
}

\begin{abstract}
Аннотация: В статье показана сущность рефлексии в педагогической науке, которая состоит во взгляде на себя и свои действия, эмоции, душевные состояния «со стороны». Рефлексия способствует самообучению, самоанализу и самоконтролю на всех этапах обучения, позволяет нам не только разобраться в себе, но и дает возможность понять окружающих нас людей.

Ключевые слова: рефлексия; педагогика; рефлексивный подход; психология; саморазвитие; самоанализ; модель рефлексивного механизма; функции рефлексии; классификация рефлексии
\end{abstract}

\section{REFLEXIVE APPROACH AS A PEDAGOGICAL ISSUE}

\author{
L. S. Burdyakova \\ Moscow University for the Humanities
}

\begin{abstract}
The paper examines the essence of reflection in the pedagogical science, which comprises an outlook on one's inner-self and his/her actions, emotions, states of mind "from the outside". Reflection promotes self-teaching, self-analysis, and self-control at all stages of education. It allows us not only to understand ourselves, but also provides an opportunity to comprehend the people around us.
\end{abstract}

Keywords: reflection; pedagogy; reflexive approach; psychology; personal development; self-analysis; model of reflexive mechanism; functions of reflection; classification of reflection

Повышенный интерес к внедрению рефлексивного подхода в педагогическую практику появился с ростом доступности научной информации в мире. Основной целью образования становится формирование у личности навыка постоянного саморазвития (Джига, 2009). Этот навык важен как готовым специалистам, так и тем, кто только становится на свой профессиональный путь. На основании исследований Л. П. Гимпель, оценка эффективности развития данного навыка осуществляется ими посредством рефлексивного подхода. Основной составляющей рефлексивного подхода является сама рефлексия (Гимпель, 2010: Электр. ресурс). 
На современном этапе развития науки при обозначении рефлексии мы отталкиваемся от умозаключений древнегреческих философов, один из которых - Аристотель называл ее мышлением о мышлении. Известные сократовские диалоги выступают в качестве организованного акта рефлексии непосредственно собеседника самого Сократа. Подтверждение тому мы находим в изречении Сократа - «Познай самого себя» (см.: Кессиди, 1988: 220), сводимое к совету постигнуть свои способности и осознать свои возможности, к некоему утверждению необходимости объективной самооценки. Все размышления как Сократа, так и многих других древнегреческих философов над личностными переживаниями и чувствами обладают рефлексивным характером.

Г. Лейбниц и Дж. Локк трактуют рефлексию как поворот духа к собственному «Я», вся получаемая информация в ходе отражения делится на два самостоятельных потока, один из который взаимодействует непосредственно с «рефлексией» как с самопознанием, в то время другой - с разумом, на основании чего Дж. Локк понимает рефлексию как источник знаний, который порожден внутренним опытом человека (Локк, 1960: 254).

К. Маркс объясняет рефлексию через призму категории отношения. Философ использует практически все значения понятия «рефлексия», и определяет его как конкретный механизм производства знаний (см.: Растянников и др., 2002: 320), т. е. процесс непосредственно организованной и целенаправленной деятельности, а также предмет и средство познания. Обращаясь к исследованиям отечественных авторов - философов (Н. Г. Чернышевский, В. С. Соловьев, Л. М. Лопатин, Г. И. Челпанов, С. Л. Франк и мн. др.), мы выделили некоторую особенность, а именно то, что они выступали за наличие духовной активности субъекта в процессе рефлексии, что, очевидно, было обусловлено единой социальноидеологической концепцией, направленной на переустройство общества посредством совершенствования личности. Современные ученые рассматривают рефлексию как специфический акт осмысления, процесс осмысления деятельности и «самоотражения» (Рефлексия ..., 1989: 184).

Анализ психолого-педагогической литературы показал, что рефлексия для авторов выступает в качестве особого вида теоретической ретроспекции, которая реализуется в следующих функциях: критическом анализе, логическом обосновании, систематизации научного знания, выработки ценностей, целей и средств научного познания. Т. е. с точки зрения метакогнитивистской концепции, рефлексия - это способность мыслить о собственном мышлении для его совершенствования.

При рассмотрении рефлексии с точки зрения психологии, выделяют три основных процесса: 1) обращение назад; 2) познание личностью своего внутреннего мира; 3) постижение личностью социальной окружаю- 
щей действительности (Задорожнюк, 2002: 129-132).

В связи с тем, что в рамках нашего исследования процесс саморазвития и саморегуляции личности рассматривается нами с точки зрения педагогической практики, мы, опираясь на классификацию рефлексии, предложенную С. Ю. Степановым и И. Н. Семеновым (Семенов, Степанов, 1983), учитывая специфику всех ее типов, выделив основные функции каждой, получили следующую классификацию:

1) Кооперативная рефлексия, которая осуществляет реорганизацию коллективной деятельности;

2) Коммуникативная рефлексия, которая способствует смене сложившихся ранее представлений субъектов взаимодействия друг о друге;

3) Личностная рефлексия, которая способствует самоопределению личности и обоснованию им индивидуального права на некоторую степень отклонения от первоначального алгоритма с учетом специфики особенностей возникшей нестандартной ситуации;

4) Интеллектуальная рефлексия, которая осуществляет, как переосмысление, так и преобразование начальной модели самого объекта в наиболее адекватную, основываясь на вновь поступившей информации о нем.

Данная классификация позволяет экстраполировать степень зависимости конкретных функций рефлексии от разнообразия ситуаций, возможных в педагогическом процессе, рассматривая рефлексию как специальный механизм самопознания и активного переосмысления личностью своего индивидуального сознания, посредством которого возможно ее дальнейшее самосовершенствование и рост успешности в осуществляемой ею деятельности и общении.

В этой связи современные ученые выделяют основные этапы рефлексивного механизма: 1 - актуализацию смысловых структур «Я» в момент осмысления личностью конкретной проблемной ситуации; 2 - использование актуализировавшихся смыслов в процессе апробации личностью разнообразных образцов опыта и деятельности; 3 - дискредитацию актуализировавшихся смыслов в рамках выявленных личностью противоречий; 4 - инновацию основных принципов конструктивного преодоления выявленных ранее противоречий посредством нового осмысления личностью как непосредственно самой проблемной ситуации, так и самого себя конкретной проблемой; 5 - реализацию полученного целостного смысла посредством дальнейшей реконструкции содержания собственного опыта и оптимального разрешения конкретной проблемной ситуации (там же).

В этой модели основное место занимает личностно-смысловая и творческая составляющая рефлексии, что дает возможность использовать рефлексивный подход для воспитания учащихся (Белякова, 2010: 44-48). 
Необходимо отметить, что педагогика способна аккумулировать все аспекты рефлексии, отмеченные нами как в философии, так и психологии. Если ранее большинство исследований были направлены на сбор доказательной базы необходимости введения рефлексии в педагогический процесс, то в настоящее время идет осмысление ряда внутренних понятий рефлексии, рассмотрение ее на теоретическом, практическом и методическом уровнях, а также изучение возможности их пересечений, характера и степени взаимосвязи, что в свою очередь обусловлено запросами практики.

Одной из особенностей педагогической рефлексии выступает ее устремленность на глубокий самоанализ. Модернизация и связанные с ней процессы, проистекающие как в современной системе образования (такие как необходимость перехода с традиционного на личностноориентированное, гуманистическое обучение), так и в обществе в целом, выдвигают достаточно высокие требования к уровню сформированности рефлексии сознания человека и повышенному чувству ответственности за другого человека (Коршунова, 2015: 114-115).

В настоящее время наблюдаются изменения практики образовательного процесса, трансформация которых происходит на базе рефлексивных принципов и разнообразных рефлексивных технологий. Происходит и формулирование отдельных понятий, основу которых составляет непосредственно рефлексия, способные стать универсальными инструментами для осмысления рефлексивного подхода в процессе познания и преобразования педагогической практики. Рефлексивный подход находит новые возможности во взаимодействии «учитель - ученик» И «ученик ученик», что помогает выстраивать наиболее эффективный способ усвоения учебного материала (Гимпель, 2010).

На основании проведенного нами теоретического анализа разнообразных источников, посвященных освещению темы нашего исследования, под рефлексивным подходом мы понимаем такую методологическую ориентацию, используемую в педагогической деятельности, которая позволяет, опираясь на конкретную систему взаимосвязанных принципов, понятий и способов действий, обеспечить формирование и развитие необходимых рефлексивных умений и навыков.

Человеческая психика в момент обучения часто реагирует на возникающие проблемы страхом совершения ошибки, и когда эта ошибка происходит, она блокирует интерес и активность дальнейшего развития личности в данной области знаний. В связи с этим становится важным уметь контролировать свои эмоции при возникновении ошибок. Рефлексивный подход помогает этому научиться.

Исходя из вышесказанного, мы относим рефлексивный подход к числу тех педагогических подходов, методологические основания которых 
построены на онтологических представлениях различных гуманитарных наук (философии, антропологии, социологии, культурологии и др.). Рефлексивный подход предполагает особою ценностную ориентацию: личность, осознанный выбор (в противовес психологическому - свободный выбор), общество. Таким образом, рефлексивный подход в педагогической науке можно рассматривать как самостоятельный подход на основании наличия глубокой гуманитарной базы и особой ценностной ориентацией.

\section{СПИСОК ЛИТЕРАТУРЫ}

Белякова, Е. Г. (2010) Модель смыслоориентированного образования // Знание. Понимание. Умение. № 3. С. 44-48.

Гимпель, Л. П. (2010) Педагогическая рефлексия в структуре профессиональной деятельности / Личность, семья и общество: вопросы педагогики и психологии : сб. ст. по матер. I междунар. науч.-практ. конф. № 1. Часть I. [Электронный ресурс] // СибАк. URL: https://sibac.info/conf/ pedagog/i/35242 (дата обращения: 04.06.2017).

Джига, Н.Д. (2009) Самоуправление, самоизменение личности студента как фактор успешности развития // Знание. Понимание. Умение. № 3. C. 206-210.

Задорожнюк, И. Е. (2002) Рефлексивные процессы: психологопедагогические аспекты // Вопросы психологии. № 1. С. 129-132.

Кессиди, Ф. Х. (1988) Сократ. 2-е изд., доп. М. : Мысль. 220 с.

Коршунова, И. Г. (2015) Способы применения рефлексивного подхода в профессиональной подготовки будущих специалистов (педагогический аспект) // Инновационная наука. № 4-2. С. 114-116.

Локк, Дж. (1960) Опыт о человеческом разумении // Локк Дж. Избранные философские произведения : в 2 т. М. : Соцэкгиз. Т. І. 254 с.

Растянников, А. В., Степанов, С. Ю., Ушаков, Д. В. (2002) Рефлексивное развитие компетентности в совместном творчестве. М.: Пер Сэ. 320 с.

Рефлексия в науке и обучении (1989) / отв. ред. И. С. Ладенко, О. А. Донских и др. Новосибирск : Изд-во Сиб. отд. АН СССР. 184 с.

Семенов, И. Н., Степанов, С. Ю. (1983) Рефлексия в организации творческого мышления и саморазвития личности // Вопросы психологии. № 2 . C. 35-42.

Дата поступления: 06.08.2017.

Бурдякова Любовь Сергеевна - заведующая отделом организации научных мероприятий управления науки, аспирантуры и докторантуры и научной работы; аспирант кафедры педагогики и психологии высшей школы Московского гуманитарного университета. Адрес: 111395, 
Россия, г. Москва, ул. Юности, д. 5, корп. 6. Тел.: +7 (499) 374-75-40. Эл. адрес: Lburdyakova@mosgu.ru. Научный руководитель - д-р пед. н., проф. Л. В. Романюк.

Burdyakova Lubov' Sergeevna, Head, Department of Organization of Scientific Events, Department of Science, Postgraduate and Doctorate Study and Scientific Research; Postgraduate Student, Department of Pedagogy and Psychology of Higher School, Moscow University for the Humanities. Postal address: 5, Yunosti St., Moscow, Russian Federation 111395. Tel.: +7 (499) 37475-40. E-mail: Lburdyakova@mosgu.ru. Scientific Adviser - L. S. Romanyuk, Doctor of Pedagogy, Professor.

\section{Для цитирования:}

Бурдякова Л. С. Рефлексивный подход как педагогическая проблема [Электронный ресурс] // Научные труды Московского гуманитарного университета. 2017, № 4. URL: http://journals.mosgu.ru/trudy/article/view/531 (дата обращения: дд.мм.гг.). DOI: 10.17805/trudy.2017.4.8 